\title{
Cross-national variations in COVID-19 outbreak in West Africa: Where does Nigeria stand in the pandemic?
}

\author{
Tolulope Osayomi ${ }^{1}$ (D) Richard Adeleke ${ }^{1} \cdot$ Olalekan John Taiwo $^{1} \cdot$ \\ Adeniyi S. Gbadegesin ${ }^{1}$ - Opeyemi Caleb Fatayo ${ }^{1}$ - Lawrence Enejeta Akpoterai ${ }^{1}$. \\ Joy Temitope Ayanda ${ }^{1} \cdot$ Judah Moyin-Jesu $^{1} \cdot$ Abdullahi Isioye $^{1}$
}

Received: 1 August 2020/Revised: 8 September 2020/Accepted: 23 October 2020/Published online: 8 November 2020

(C) Korean Spatial Information Society 2020

\begin{abstract}
Nigeria is currently the worst COVID-19 affected country in West Africa in terms of morbidity and mortality amid ECOWAS's recent proclamation of the country as the region's COVID-19 Response Champion. It is against this background that this paper analysed the geographical distribution of confirmed COVID-19 cases and fatalities in West Africa, with a view to understanding why Nigeria is at the heart of the pandemic in the subcontinent. The research relied on COVID-19 data and other health, demographic, transport, economic indicators from published sources. Pearson correlation technique and simple linear regressions were useful in discerning associations between COVID-19 and explanatory factors in West Africa. In order of importance, Nigeria, Ghana and Senegal were the top three on the morbidity list while Nigeria, Mali and Niger had the largest number of fatalities as at June 11, 2020. Results show that the population size and air traffic had significant impact on both COVID-19 morbidity and mortality in West Africa. In addition, Nigeria's large population size and high air traffic volume did not only increase its susceptibility to the viral infection but also accounted for its being an outlier in the sub-continent. The study recommends that a cautious and gradual reopening of the borders should be considered by member states of the sub-region while behavioural avoidance measures are being enforced till a vaccine is found.
\end{abstract}

Electronic supplementary material The online version of this article (https://doi.org/10.1007/s41324-020-00371-5) contains supplementary material, which is available to authorized users.

Tolulope Osayomi

osayomi@yahoo.com

1 COVID-19 Mapping Lab, Department of Geography, University of Ibadan, Ibadan, Nigeria
Keywords COVID-19 - Pandemic · Non-Pharmaceutical interventions $\cdot$ Nigeria $\cdot$ Economic Community of West African States

\section{Introduction}

On December 31, 2019, a cluster of pneumonia-like infection was detected in Wuhan of Hubei Province, China. The infection is claimed to have originated from a seafood market in the city. It was first named nCov19 and later relabelled as COVID-19 or better known as the Coronavirus Disease. The virus is transmitted by air droplets; spreading through person-to-person contact. Its symptoms include cough, fever, headache, shortness of breath, and respiratory difficulty. Given its magnitude, the World Health Organization (WHO) on the 30th January 2020, classified COVID-19 as a Public Health Emergency of International Concern and subsequently a pandemic on March 11, 2020 [1]. As of June 11, there were over 7 million confirmed cases and over 400,000 deaths that were associated with COVID-19 [2].

Reports from the Africa Centre for Disease Control (Africa CDC) [3] affirmed that the first case of coronavirus in Africa was reported in Egypt on 14th February, 2020. The second case was reported in Algeria on the 25th February, 2020, increasing the number of affected countries in Africa to two. Since then, there has been a rapid increase in the number of confirmed COVID-19 cases on the continent and in its adjoining islands [3]. Most of the index cases were reported to have been imported. For instance, according to the National Institute for Communicable Diseases (NICD) [4], South Africa, and the Nigeria Centre for Disease Control (NCDC) [5], the index cases in both South Africa and Nigeria were from travellers who 
flew in from Italy, which at the time was slowly emerging as Europe's epicentre. The virus is now present in every part of Africa; contrary to earlier reports that the coronavirus may not survive in Africa because of the continent's generally high temperature [6].

Nigeria, on the 27th February, 2020, became the third in Africa, and the first in West Africa to report a case of COVID-19. Subsequently, the virus later reached the other fourteen countries of West Africa at different points in time. However, it is pertinent to note here at the onset of the COVID-19 outbreak in West Africa, Ghana, prior to 17 May, 2020, was the worst affected country in the region. Later, Nigeria overtook Ghana, becoming the country with the largest number of infections on the 17th May, 2020 [7]. Since then, it has not only remained the country with the highest number of COVID-19 morbidity but also the largest mortality. This unenviable status is against the backdrop of the Economic Community of West African States (ECOWAS)'s recent proclamation of Nigeria as the Regional Champion against COVID-19 [8] with the hope that Nigeria would lead and effectively coordinate the rest of the subcontinent in the prevention and control of COVID-19.

Within the context of West Africa, Nigeria is a major regional player. The country has the largest population size (206.1 million) in West Africa [9] which is more than 50 percent of the sub-region's population. Besides the fact it is home to the headquarters of the Economic Community of West African States (ECOWAS), Nigeria is a strong pillar in the political and economic affairs of this regional community. In terms of air passenger traffic, Lagos, Nigeria is West Africa's major air traffic hub with about 2 million passengers in 2019 [10]. West Africa, however, had earlier faced an Ebola outbreak in 2014, which the World Health Organisation (WHO) had declared as a Public Health Emergency of International Concern.

The relatively poor health infrastructure in the subcontinent partly accounted for the rapid spread of Ebola in some parts. The literature shows two conflicting viewpoints on how West Africa's Ebola outbreak history makes its (un)prepared for COVID-19. On one hand, the generally dysfunctional health sector was envisaged to hamper West Africa's preparedness against COVID-19. [6:e631] support this view: "many west African countries have poorly resourced health systems rendering them unable to quickly scale up an epidemic response". On the other hand, West Africa, given the Ebola episode, would be better prepared, comparatively speaking, for COVID-19 because of the quality of disease surveillance, testing capacity and contact tracing [11]. The background information on Nigeria and West Africa therefore provides a strong justification for this enquiry. We certainly hope that these findings would not only point Nigeria but also West Africa in the right direction with respect to an effective response in disease prevention and control.

Based on the foregoing, the thrust of this research is to (1) examine the geographical distribution of COVID-19 morbidity and mortality in West Africa (2) identify the country level drivers of COVID-19 and (3) determine the position of Nigeria in the health crisis within West Africa using retrospective COVID-19 data. The paper is structured as follows. The section that follows the introduction touches on the data sources and methods. The third section shows the study results. The fourth section contains the discussion of the results. Finally, the paper ends with conclusion and recommendation.

\section{Methods}

Secondary data from several published sources such as the West African Health Organisation (WAHO) [7], 2019 World Population Data Sheet of the Population Reference Bureau [12], African Statistical Yearbook 2019 of the African Development Bank (AfDB) [13], Diabetes Atlas of the International Diabetes Federation (IDF) [14], the United Nations Development Programme (UNDP)'s Human Development Report 2019 [15] and the International Civil Aviation Organization (ICAO) [16] formed the basis of the study's analysis. Retrospective COVID-19 morbidity and mortality cases in fifteen countries of West Africa as at June 11, 2020 were obtained from the WAHO while the country level information on air traffic movement, population size, urban population, fine particulate matter, tourist arrivals, net migration, population below the poverty line, percent population 65 years and above, population density, doctors/hospitals per 10,000 persons, human poverty index, human development index, poverty incidence, paved roads, population using basic sanitation facilities and diabetes prevalence were culled from PRB [12], AFDB [13], IDF [14], UNDP [15] and ICAO [16]. These variables were selected based on their perceived association with COVID19 [17, 18].

Pearson correlation technique was useful in discerning the nature of relationship between the spread of COVID-19 and explanatory factors, while the simple linear regression (the step-wise technique) identified the impact of significant explanatory variables on the geographical distribution of COVID-19 cases in West Africa. Scatter plots were designed to give the visual clarity to Nigeria's relative position in the pandemic in West Africa. Three dimensional (3D) proportional circle maps showing the geographical distribution of COVID-19 in West Africa were designed to depict the magnitude of the pandemic, using ArcGIS 10.4 version. Statistical data analysis was possible with SPSS version 20. 


\section{Results}

\subsection{Geographical distribution of COVID-19 morbidity}

On June 11, 2020, there were a total of 46,433 confirmed cases in the sub-region, however, with substantial variations. The country with the largest number of COVID-19 cases in West Africa was Nigeria (14,554), followed by Ghana $(10,358)$ and Senegal (4759) while the smallest numbers were found in The Gambia (28), Benin (305) and Togo (524) (Fig. 1).

\subsection{Geographical distribution of COVID-19 mortality}

Up till June 11, 2020, there were 886 COVID-19 related deaths. Like morbidity, Nigeria had the largest number of deaths associated with the disease (387). However, Mali and Niger followed with 97 and 65 deaths, respectively. Again, The Gambia (1) and Benin (4) had the lowest number of deaths as at the time, followed by Cabo Verde (6) (Fig. 2).

\subsection{Associations with COVID-19}

\subsubsection{Spatial Correlations between Morbidity and Mortality}

There appears to be a spatial co-variation between COVID19 morbidity and mortality. In other words, states with higher morbidity would correspondingly have higher death rates. Thus, Pearson correlation was used to test this hypothesis. From the results in Table 1, the relationship between morbidity and mortality was largely positive and strong $(r=0.776)$.

\subsection{Relationship between COVID-19 and explanatory variables}

The results of the correlational analysis are set out in Table 1. Coincidentally, COVID-19 morbidity and mortality have strong and positive association with population size and air traffic. Population size has the strongest association with morbidity $(r=0.824)$ and mortality $(r=0.978)$. Air traffic is also positively related with morbidity $(r=0.700)$ and mortality $(\mathrm{r}=0.938)$.

The scatter plots not only depict the relationship between COVID-19 and significant risk factors but also

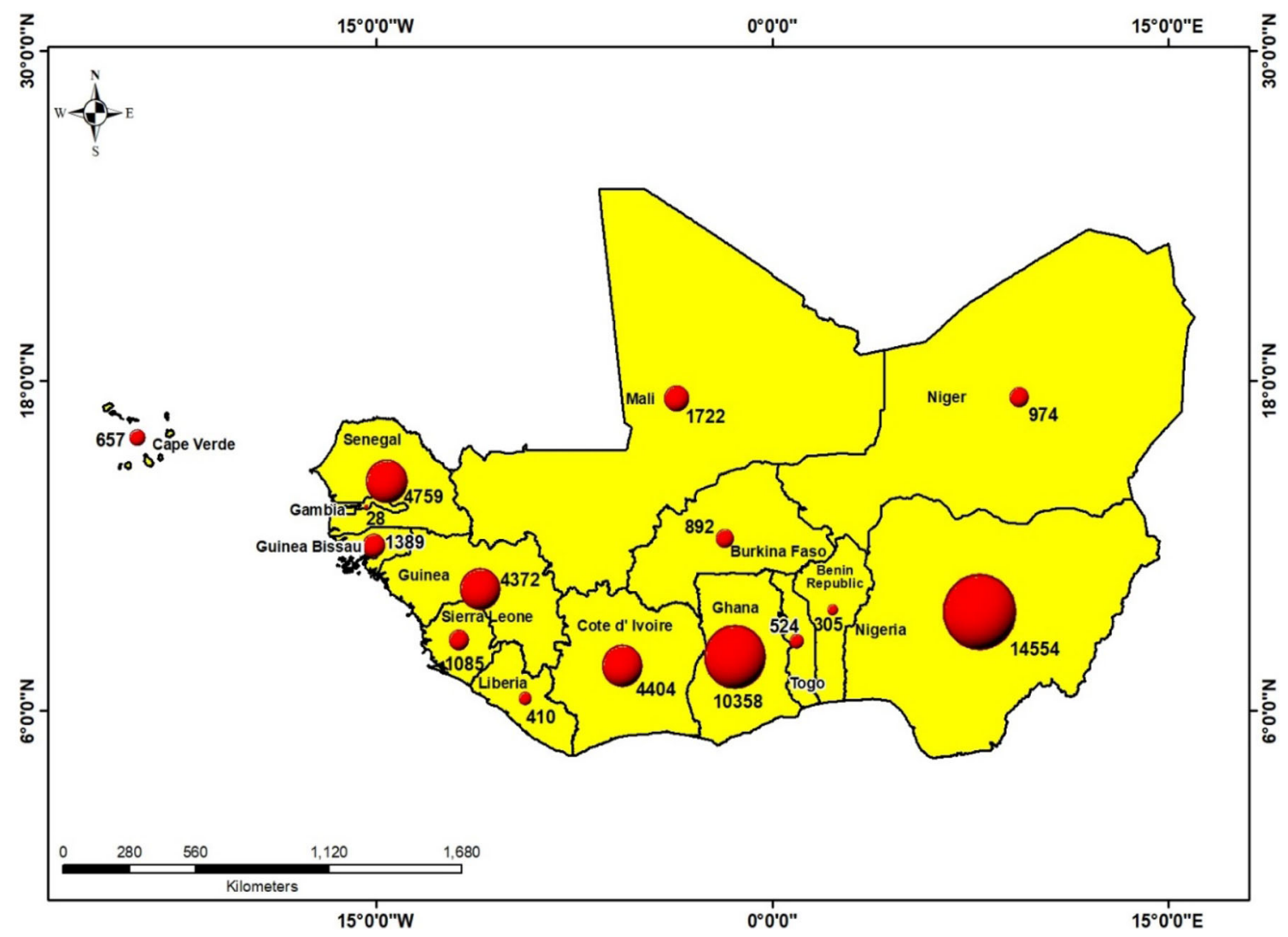

Fig. 1 Geographical distribution of COVID-19 morbidity in West Africa (June 11, 2020) 


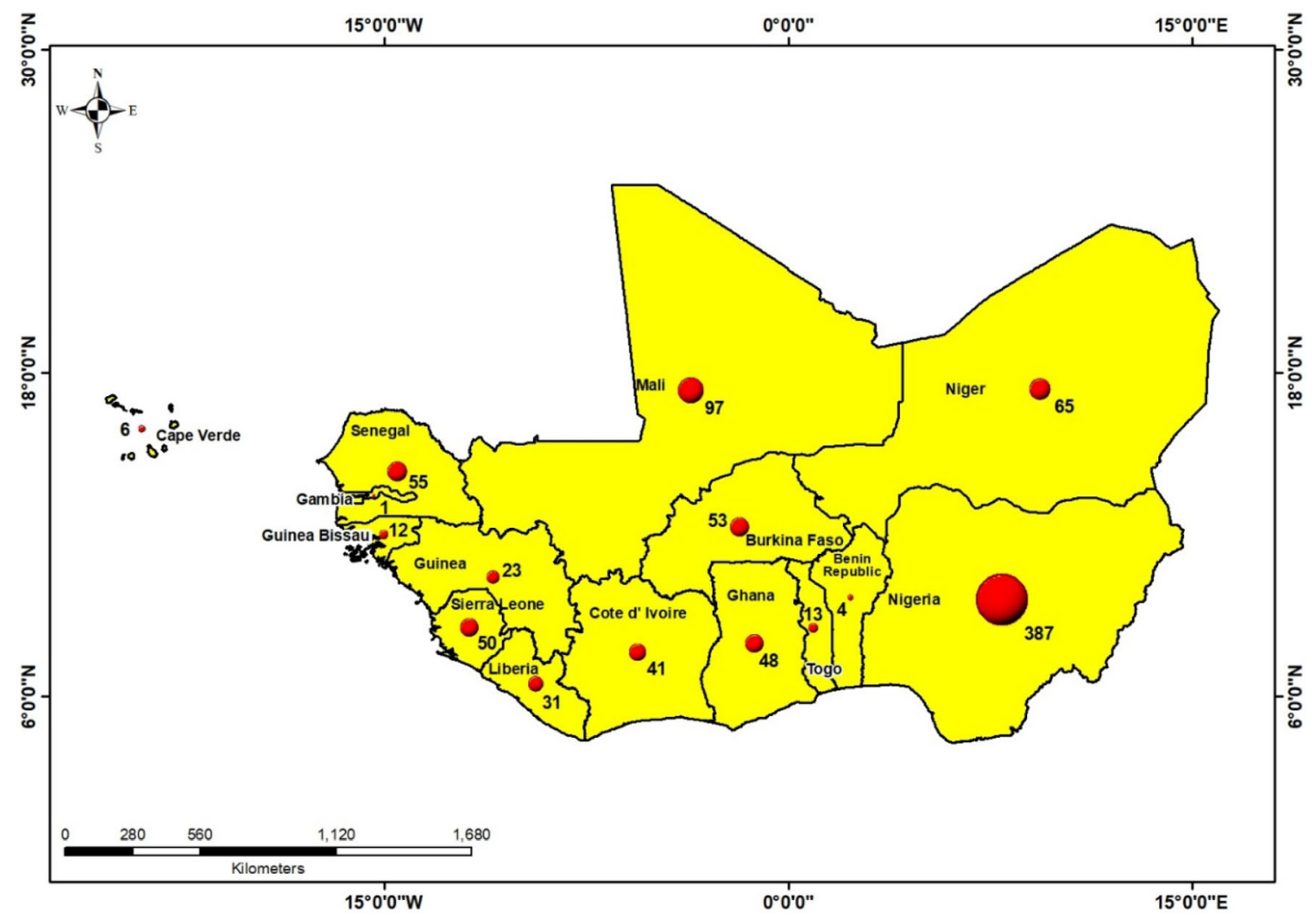

Fig. 2 Geographical distribution of COVID-19 mortality in West Africa (June 11, 2020)

Table 1 Bivariate correlations Source: Authors' computation

\begin{tabular}{lll}
\hline Variable & Morbidity & Mortality \\
\hline Population 65 years and above & -0.037 & -0.161 \\
Access to Safe water & 0.158 & -0.126 \\
\% Paved Roads & -0.330 & -0.291 \\
Basic sanitation facilities & 0.110 & 0.134 \\
Fine Particulate Matter & 0.057 & 0.344 \\
\%Urban population & 0.189 & -0.022 \\
Diabetes National Prevalence & 0.114 & 0.290 \\
Doctors & 0.111 & -0.011 \\
Hospital beds & -0.152 & 0.007 \\
Human Poverty Index & -0.210 & 0.045 \\
Human Development Index & 0.377 & 0.038 \\
COVID-19 Morbidity & - & $\mathbf{0 . 7 7 6} * *$ \\
COVID-19 Mortality & $\mathbf{0 . 7 7 6 * *}$ & - \\
Net Migration & 0.308 & 0.158 \\
Poverty incidence & -0.047 & 0.296 \\
Population density & 0.093 & -0.069 \\
Population size & $\mathbf{0 . 8 2 4 * *}$ & $\mathbf{0 . 9 7 8} * *$ \\
Air traffic & $\mathbf{0 . 7 0 0 * *}$ & $\mathbf{0 . 9 3 8 * *}$ \\
Tourist arrivals & -0.106 & -0.152 \\
\hline
\end{tabular}

Significant correlations in bold print; *: $0.05 ; * *: 0.01$ shows the position of each of the 15 countries of West Africa. Figures 3, 4, 5 and 6 show Nigeria is an outlier in the sub-continent because of its large population size and high air traffic movement. It far exceeds the other 14 countries. Thus, Nigeria occupies an exceptional position in the pandemic.

\subsection{Regression results}

Table 2 presents the results of the simple linear regression between COVID-19 and each of the explanatory variables. This was done to explore the individual effects of the independent variables. Table 3 shows the results of the bivariate regression models. With regard to morbidity, population size and air traffic were significant at 0.000 . On one hand, population size was positive and accounted for 67.8 percent in the observed variation in morbidity. On the other hand, air traffic explained 49 percent of the total variation in morbidity. With respect to mortality, population size and air traffic were also statistically significant. Population size was responsible for 95.6 percent of the variance in mortality while air traffic contributed 87.1 percent of total variation in mortality.

To explore the joint contribution of these two variables, two regression models were estimated for morbidity and mortality using the stepwise approach. Interestingly, 
Fig. 3 Relationship between COVID-19 and Population (with emphasis on Nigeria's relative position)

Fig. 4 Relationship between COVID-19 morbidity and air traffic (with emphasis on Nigeria's relative position)
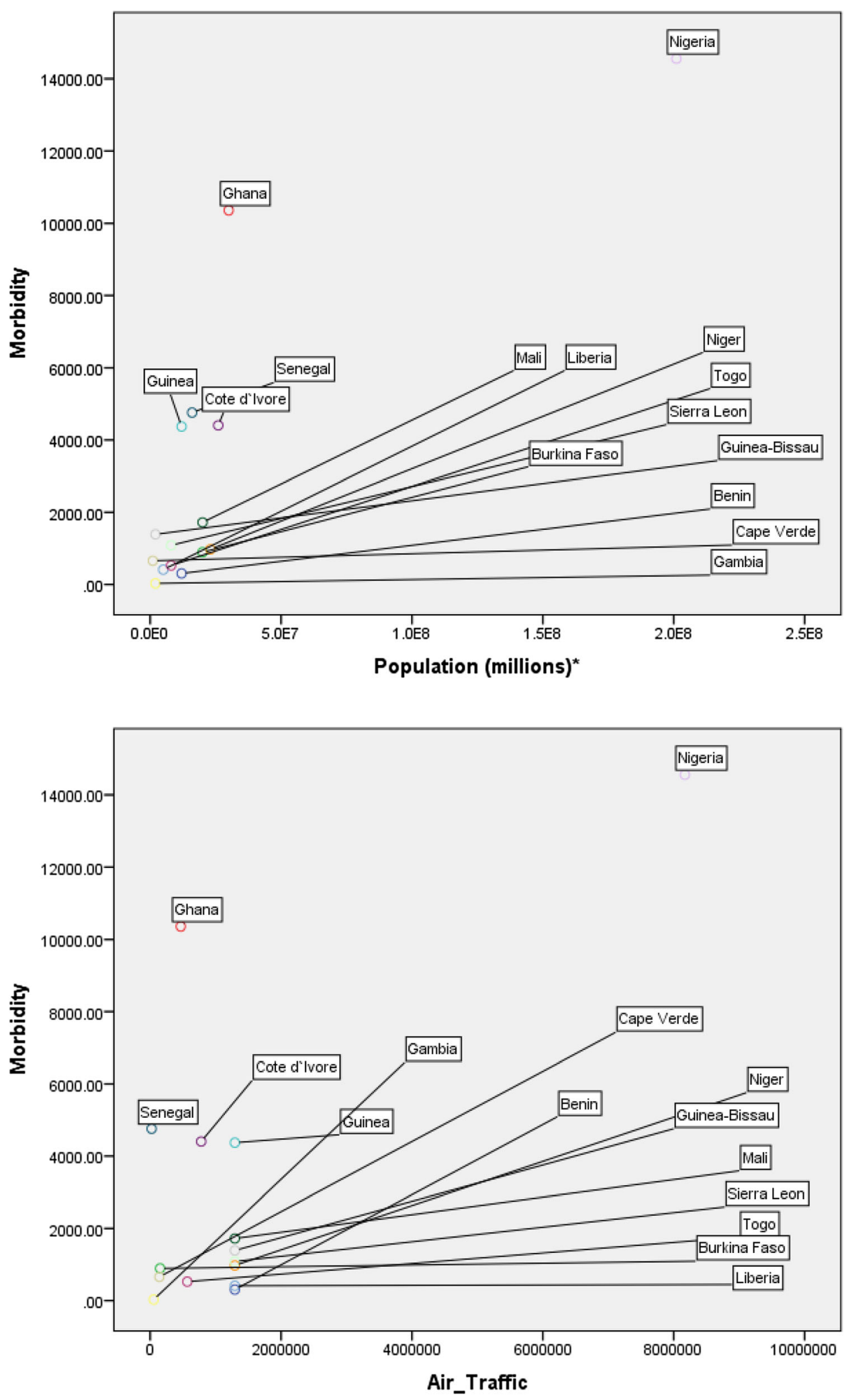

population size is the only significant predictor of morbidity and mortality (Table 2). Population size accounts for nearly 70 percent and nearly 96 percent of morbidity and mortality respectively (Table 2 ) 
Fig. 5 Relationship between COVID-19 mortality and population (with emphasis on Nigeria's relative position)

Fig. 6 Relationship between COVID-19 mortality and air traffic (with emphasis on

Nigeria's relative position)
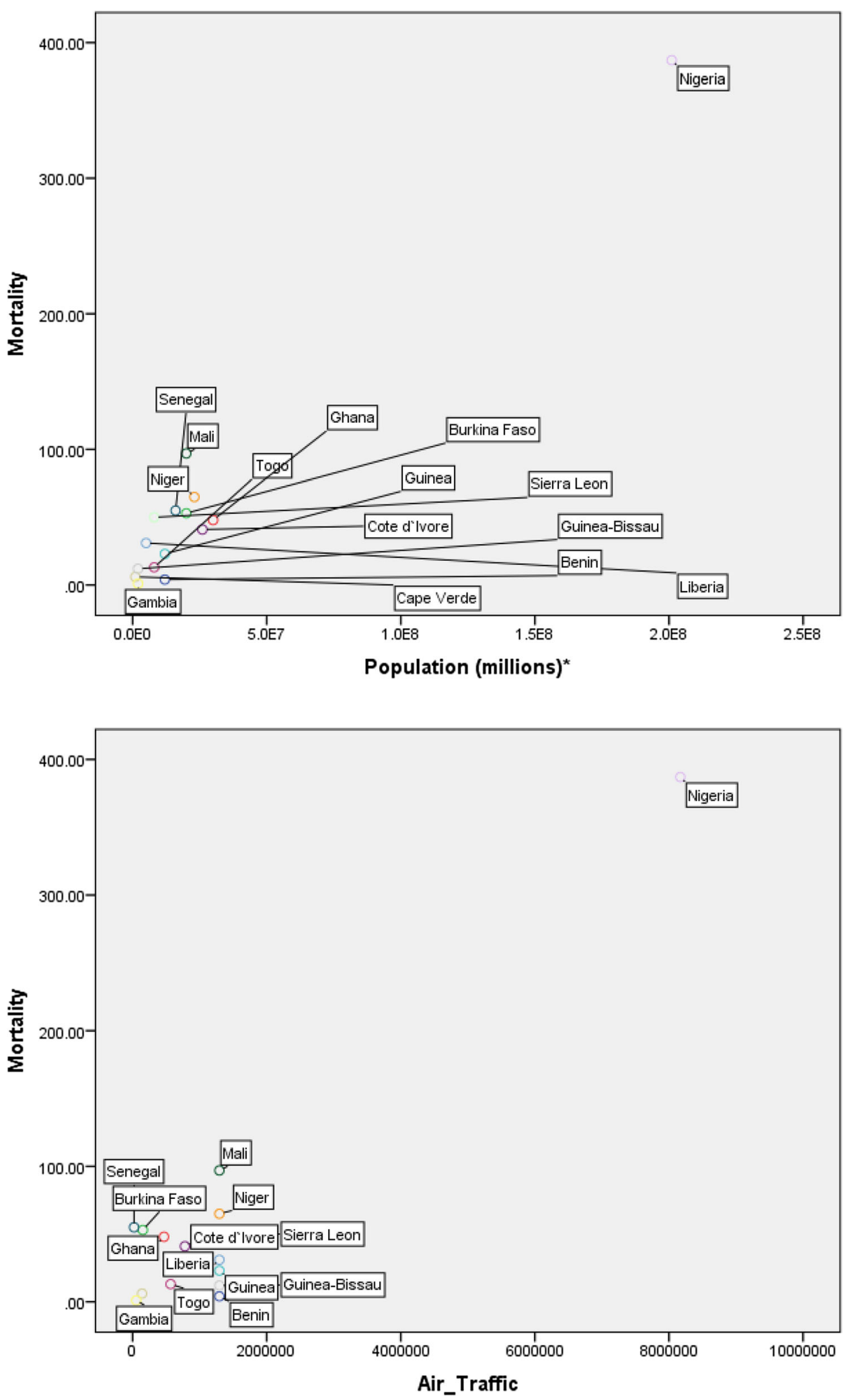
Table 2 Bivariate Regression Results

\begin{tabular}{llllll}
\hline Morbidity & Variable & Coefficient & $\mathrm{R}^{2}$ & $\mathrm{~F}$ & $\mathrm{Sig}$ \\
\hline & Population & 0.824 & 0.678 & 27.395 & 0.000 \\
& Air traffic & 0.700 & 0.490 & 12.507 & 0.004 \\
\hline Mortality & Variable & Coefficient & $\mathrm{R}^{2}$ & $\mathrm{~F}$ & $\mathrm{Sig}$ \\
\hline \multirow{4}{*}{ Population } & 0.978 & 0.956 & 283.496 & 0.000 \\
& Air traffic & 0.938 & 0.871 & 95.453 & 0.000
\end{tabular}

Table 3 Stepwise Regression Results

\begin{tabular}{lllrl}
\hline Dependent variable & $\mathrm{R}^{2}$ & Adjusted $\mathrm{R}^{2}$ & $\mathrm{~F}$ value & $\mathrm{p}$ \\
Morbidity & 0.678 & 0.653 & 27.395 & 0.000 \\
Mortality & 0.956 & 0.953 & 283.496 & 0.000 \\
\hline
\end{tabular}

\section{Discussion}

The study examined the cross national variations in COVID 19 in West Africa with Nigeria as the COVID-19 epicenter. As at the time of writing, West Africa had a total number of 46,433 confirmed cases of COVID-19 with Nigeria accounting for 31.34 percent of the total confirmed cases [7], making it the most afflicted in the sub region. In order of relative importance, Nigeria, Ghana and Senegal were the top three on the morbidity list while Nigeria, Mali and Niger had the largest number of fatalities as at June 11, 2020. Population size and air traffic were the major determinants of COVID 19 cases and mortality.

Nigeria's large population size and large air traffic movement put it at the centre of the pandemic in West Africa. It is a well-known fact that Nigeria is the most populous country in Africa with over 200 million people [9] of which 50 percent live in urban areas [12]. These urban settlements are largely characterized by poor housing conditions as well as overcrowded informal settlements $[15,19]$ which aid the spread of highly contagious diseases. A good reference point is Lagos, the most populated city in West Africa and Africa, is currently Nigeria's COVID-19 epicentre [18], where about 60 percent of its residents live in slums and informal settlements with limited access to water, poor sanitation and other basic services [20]. As earlier mentioned, the transmission strongly depends on close physical contact. Given this condition, a large and susceptible population would greatly favour the spread of infectious diseases.

Our finding is confirmed by [17]'s multi-country analysis of COVID-19 outbreak across the globe in which population size was a significant factor. It is also corroborated by similar studies in the United States [21], Nigeria
[18, 22], China [23], Iran [24], among others. As part of a number of behavioural avoidance measures against the disease, the World Health Organization [2] consistently recommends physical distancing by maintaining at least one metre from the next person. The reason for this is to avoid being infected by respiratory or oral droplets of an infected person. However, physical distancing is quite difficult to maintain in densely populated environments. Similarly, the effect of population size on COVID 19 mortality in Nigeria strongly suggests that COVID-19 mortality tends to be higher in countries with larger population. This is similar to the situation in Lombardy where its large population may have accounted for the high cases of COVID 19 and mortality [25]. This is also the case in Madrid, Spain's most populous city which had the highest cases of COVID 19 and mortality [26].

With regard to air traffic as a risk factor of COVID 19, Nigeria has the tenth busiest airport in Africa and first in West Africa [27]. Over the years, Nigerian airports have witnessed increased patronage. According to the National Bureau of Statistics [28], Nigeria recorded 14.82 million air travellers (both domestic and international) in 2018 compared to 14.26 million in 2017. The number of international air travellers into Nigeria has risen from 9.16 percent in 2017 to 38.8 percent in 2018 [28]. As a matter of fact, Nigeria's index case was imported to Nigeria from Italy via international air travel. This strongly indicates that human mobility no doubt facilitates the transmission of the virus [18, 29]. Across the world, more than 80 countries had imposed travel bans to limit the spread of the virus [30]. Our finding is again consistent with that of Lau et al. [31] in China and Zhaung et al., [32] in Iran.

\section{Conclusion}

There were striking cross national variations in COVID 19 in West Africa, with Nigeria as the COVID-19 epicentre of the region. The novel infection spreads rapidly in countries with large population and high air passenger traffic. Besides, Nigeria's demographic and regional standing puts the whole region at great risk if the land borders and airspace are hastily re-opened. Like other countries in the world, Senegal and Togo resumed international flights on July 15, 2020 and August 1, 2020, respectively [33, 34] while Nigeria and Ghana are to reopen airspace on August 21 and September, 1, 2020, respectively [35, 36].

Based on the findings and in light of recent developments, Nigeria certainly needs to live up to its mandate by strengthening the governance structures within and outside its borders so as to effectively coordinate the COVID-19 response. The study argues that a cautious and gradual reopening of the borders should be considered and adopted 
by member states of ECOWAS while the quality of disease surveillance in the region is enhanced and testing capacity is increased. This is in addition to the strict enforcement of non-pharmaceutical interventions such as physical distancing, use of face masks, and proper hand hygiene in all public spaces. Finally, airlines, domestic and international airports in West Africa should comply strictly with COVID-19 safety protocols as the search for a COVID-19 vaccine continues.

Acknowledgements This is a modified version of a paper presented at the first virtual Southwest Zonal conference of the Association of Nigerian Geographers (SWANG) from 29th to 30th June 2020.

Funding There is no funding for this research.

\section{Compliance with ethical standard}

Conflict of interest The authors declare that they have no conflict of interests.

Ethics approval This study is based on the analysis of secondary data, hence ethical approval was not required.

Consent for publication Upon acceptance, we give the consent to publish the article.

\section{References}

1. World Health Organization. (2020). Coronavirus disease (COVID-19) advice for the public. Retrieved July 5, 2020, from https://www.who.int/emergencies/diseases/novel-coronavirus2019/advice-for-public.

2. World Health Organization. (2020). Coronavirus disease (COVID 19) situation report-143. Retrieved July 5, 2020, from https:// reliefweb.int/sites/reliefweb.int/files/resources/20200611-covid19-sitrep-143.pdf.

3. Africa Centre for Disease Control. (2020). Outbreak Brief: Novel Coronavirus (2019-nCoV) in China. 22 January, 2020.

4. National Institute for Communicable Diseases (2020). COVID-19 daily report. Retrieved July 29, 2020, from https://www.nicd.ac. zal.

5. Nigeria Centre for Disease Control. (2020). COVID-19 Nigeria. Retrieved July 10, 2020, from https://covid19.ncdc.gov.ng/.

6. Alvarez, M. M., Jarde, A., Usuf, E., Brotherton, H., Bittaye, M., Samateh, A., et al. (2020). COVID-19 pandemic in West Africa. The Lancet Global Health, 8, 631-632.

7. West Africa Health Organization. (2020). Coronavirus disease (COVID-19) outbreak. Retrieved July 5, 2020, from https://www. wahooas.org/web-ooas/.

8. The Punch News Paper. (2020). ECOWAS leaders appoint Buhari champion of COVID 19 response. Retrieved July 18, 2020, from https://punchng.com/ecowas-leaders-appoint-buharichampion-of-covid-19-response/.

9. Population Reference Bureau. (2020). 2020 World Population Data Sheet. Washington: Population Reference Bureau.

10. Adesoji, B.S. (2020). Air travellers across Nigerian Airports hit 8.5 million in 6-month. Retrieved July 18, 2020, from https:// nairametrics.com/2020/01/02/air-travellers-across-nigerian-air ports-hit-8-5-million-in-6-month/\#: :text=Murtala\%
20Muhammed\%20Airport\%20recorded\%202.003,0.980\%20mil lion\%20within\%20the\%20period.

11. Ihekweazu, C., \& Agogo, E. (2020). Africa's response to COVID-19. BMC Medicine, 18, 1-3.

12. Population Reference Bureau. (2019). 2019 World Population Data Sheet. Washington: Population Reference Bureau.

13. Africa Development Bank. (2019). The African Statistical Yearbook 2019. Retrieved July 18, 2020, from https://www.afdb. org/en/documents/document/the-african-statistical-yearbook2019-109564.

14. International Diabetes Federation. (2019). IDF diabetes atlas. Retrieved July 15, 2020, from https://www.diabetesatlas.org/en/.

15. United Nations Development Programme. (2020). The COVID19 Pandemic: Socio-Economic Impact of the COVID-19 Pandemic in Nigeria Briefing Paper 1.

16. International Civil Aviation Organisation. (2019). Statistics. Retrieved July 21, 2020, from https://www.icao.int/sustainability/ Pages/Statistics.aspx.

17. Iyanda, A. E., Adeleke, R., Lu, Y., Osayomi, T., Adaralegbe, A., Lasode, M., et al. (2020). A retrospective cross-national examination of COVID-19 outbreak in 175 countries: a multiscale geographically weighted regression analysis (January 11-June 28, 2020). Journal of Infection and Public Health. https://doi.org/ 10.1016/j.jiph.2020.07.006.

18. Osayomi, T. (2020). Understanding the Geography of COVID-19 Transmission in Nigeria. Retrieved July 3, 2020, from https:// www.researchgate.net/publication/341078393_Understanding the_geographyof_COVID-19_transmission_inNigeria.

19. Ataguba J. E. (2020). COVID-19 Pandemic, a War to be Won: Understanding its Economic Implications for Africa. Applied Health Economics and Health Policy, 1-4. Advance online publication. https://doi.org/10.1007/s40258-020-00580-x.

20. Lawanson, T. (2020). Lagos' size and slums will make stopping the spread of COVID-19 a tough task. The Conversation https:// theconversation.com/lagos-size-and-slums-will-makestoppingthe-spread-of-covid-19-a-tough-task-134723.

21. Stier, A.., Berman, M., \& Bettencourt, L. (2020). COVID-19 Attack Rate Increases with City Size (March 30, 2020). Mansueto Institute for Urban Innovation Research Paper. Available at SSRN: https://ssrn.com/abstract=3564464.

22. Olusola, A., Olusola, B., Onafeso, O., Ajiola, F., \& Adelabu, S. (2020). Early geography of the coronavirus disease outbreak in Nigeria. GeoJournal. https://doi.org/10.1007/s10708-020-102781.

23. Kasumoto, O. (2020). Global Impact of New Corona Virus and Population Issues. Retrieved July 3, 2020, from http://www.ips news.net/2020/05/global-impact-new-corona-virus-populationissues/.

24. Jahangiri, M., Jahangiri, M., \& Najafgholipour, M. (2020). The sensitivity and specificity analyses of ambient temperature and population size on the transmission rate of the novel coronavirus (COVID-19) in different provinces of Iran. Science of the Total Environment. https://doi.org/10.1016/j.scitotenv.2020.138872.

25. Tondo, L. (2020). Italian hospitals short of beds as coronavirus death toll jumps. Retrieved June 20, 2020, from https://www. theguardian.com/world/2020/mar/09/italian-hospitals-short-bedscoronavirus-death-toll-jumps.

26. Pollán, M., Pérez-Gómez, B., Pastor-Barriuso, R., Oteo, J., Hernán, M.A., Pérez-Olmeda, M., Sanmartín, J.L., Fernández-García, A., Cruz, I., de Larrea, N.F. \& Molina, M. (2020). Prevalence of SARS-CoV-2 in Spain (ENE-COVID): a nationwide, populationbased seroepidemiological study. The Lancet. Volume 396, Issue 10250, 22-28 August 2020, Pages 535-544.

27. Airportcodes. (2020). Top 10 busiest airports in Africa. Retrieved June 30, 2020, from https://airportcodes.io/en/blog/top-10-busi est-airports-in-africa/. 
28. National Bureau of Statistics. (2020). Air transportation data. Retrieved July 20, 2020, from https://nigerianstat.gov.ng/elibrar y?queries[search]=air\%20transport.

29. Jiang, J., \& Luo, L. (2020). Influence of population mobility on the novel coronavirus disease (COVID-19) epidemic: based on panel data from Hubei. China. Global Health Research and Policy, 5, 30.

30. The Economist. (2020). More than 80 countries have imposed travel bans to curb the new coronavirus. Retrieved July 21, 2020, from https://www.economist.com/graphic-detail/2020/03/16/ more-than-80-countries-have-imposed-travel-bans-to-curb-thenew-coronavirus.

31. Lau, H., Khosrawipour, V., Kobach, P., Mikolajczk, A., Ichii, H., Zacharski, M., et al. (2020). The association between international and domestic air traffic and the coronavirus (COVID-19) outbreak. Journal of Microbiology, Immunology, and Infection, 53(3), 467-472.

32. Zhuang, Z., Zhao, S., Lin, Q., Cao, P., Lou, Y., Yang, L., et al. (2020). Preliminary estimation of the novel coronavirus disease (COVID19) cases in Iran: a modelling analysis based on overseas cases and air travel data. Int. J. Infect, 94, 29-31.
33. APA News. (2020). Covid-19: Senegal reopens airport to international flights. Retrieved July 20, 2020, from http://apanews.net/ en/news/covid-19-senegal-reopens-airport-to-internationalflights.

34. Gardaworld. (2020). Togo: Flight operations to resume August 1/update 4. Retrieved June 30, 2020, from https://www.garda. com/crisis24/news-alerts/365231/togo-flight-operations-toresume-august-1-update-4.

35. Akinkuoto, E. (2020). Nigeria resumes international flights Aug 29 - Minister. Retrieved July 21, 2020, from https://punchng. $\mathrm{com} /$ breaking-nigeria-resumes-international-flights-aug-29-minis ter/.

36. Begum, H. (2020). Ghana And Nigeria Set To Resume International Flights. Retrieved July 5, 2020, from https://simpleflying. com/ghana-nigeria-international-flights/.

Publisher's Note Springer Nature remains neutral with regard to jurisdictional claims in published maps and institutional affiliations. 